\title{
On the Compatibility of Dialogism and Dialectics: The Case of Mathematics Education and Professional Development
}

DOI:

10.1080/10749039.2019.1686026

\section{Document Version}

Accepted author manuscript

Link to publication record in Manchester Research Explorer

\section{Citation for published version (APA):}

Williams, J. (2019). On the Compatibility of Dialogism and Dialectics: The Case of Mathematics Education and Professional Development. Mind, Culture, and Activity, 27(1), 70-85.

https://doi.org/10.1080/10749039.2019.1686026

\section{Published in:}

Mind, Culture, and Activity

\section{Citing this paper}

Please note that where the full-text provided on Manchester Research Explorer is the Author Accepted Manuscript or Proof version this may differ from the final Published version. If citing, it is advised that you check and use the publisher's definitive version.

\section{General rights}

Copyright and moral rights for the publications made accessible in the Research Explorer are retained by the authors and/or other copyright owners and it is a condition of accessing publications that users recognise and abide by the legal requirements associated with these rights.

\section{Takedown policy}

If you believe that this document breaches copyright please refer to the University of Manchester's Takedown Procedures [http://man.ac.uk/04Y6Bo] or contact uml.scholarlycommunications@manchester.ac.uk providing relevant details, so we can investigate your claim.

\section{OPEN ACCESS}




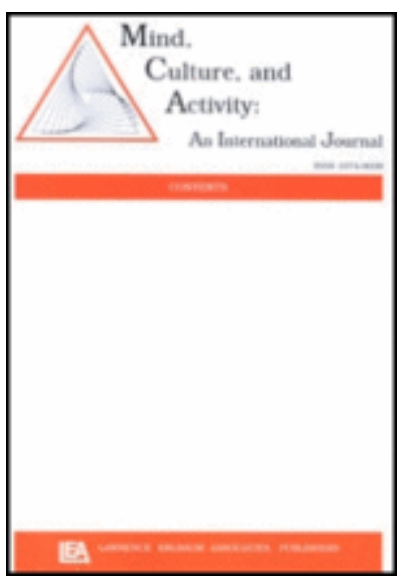

On the Compatibility of Dialogism and Dialectics: The Case of Mathematics Education and Professional Development

\begin{tabular}{|r|l|}
\hline Journal: & Mind, Culture, and Activity: An International Journal \\
\hline Manuscript ID & MCA-18-75.R3 \\
\hline Manuscript Type: & Original Article \\
\hline Keywords: & Dialogism, Bakhtin, Dialectics, Hegel, Vygotsky \\
\hline
\end{tabular}

SCHOLARONE ${ }^{\text {TH }}$

Manuscripts 
On the compatibility of dialogism and dialectics: The case of mathematics education and professional development

Julian Williams

Manchester Institute of Education, University of Manchester, UK

Julie Ryan

Faculty of Education, Manchester Metropolitan University, UK

Corresponding author: Julian.Williams@manchester.ac.uk 


\title{
On the compatibility of dialogism and dialectics: The case of mathematics education and professional development
}

\begin{abstract}
We argue that the distinction between dialogue (after Bakhtin) and dialectics (after Hegel, Marx, Vygotsky), is of key importance to learning-teaching and to mathematics education. Some followers of Bakhtin have argued that these concepts are irreconcilable, or incompatible, since dialectics implies and dialogism implicitly denies the requirement of telos (i.e., a targeted endpoint). On the contrary, we argue for compatibility; dialogism can allow for the progress implied by dialectics, but its teleology is inherent in its efficacy in practice rather than in any pre-defined endpoint. We show how a mathematical or professional dialogue can involve dialectical negations and supersession, thus providing for progress or development, without loss of dialogism. Our case is taken from a lesson study in which progress emerging from classroom and staffroom dialogues is interpreted in dialectical terms as developmental. The connection with Vygotsky's theory of concepts in learning-teaching and the possible generalization of the argument are discussed. We conclude that the key moments on which concept development turns are: (1) the negation by multiple, lived practices, and (2) the creative, speculative, supersession of inadequate concepts, in appropriate dialogues.
\end{abstract}

Keywords: dialogism; Bakhtin; dialectics; Hegel; Marx; professional development; mathematics; learning-teaching; Vygotsky

\section{Introduction}

This essay aims to make progress in debates ongoing in the field of socio-cultural theory about dialogism and dialectics, showing how and why this debate is a significant one for mathematics education in particular, and learning-teaching (our translation of Vygotsky's term obuchenie) and professional development in general. The key issue is highlighted most effectively in a number of papers about dialogic pedagogy by Matusov (1996, 2011) and Wegerif (2008), among others. They are inspired by a comment from Bakhtin (1986):

Take a dialogue and remove the voices (the partitioning of voices), remove the intonations (emotional and individualizing ones), carve out abstract concepts and 
On the compatibility of dialogism and dialectics

judgments from living words and responses, cram everything into one abstract consciousness - and that's how you get dialectics. (p. 147)

From this footnote of Bakhtin's, they characterize dialectics as being essentially monologic, logically proceeding to the Absolute notion, and so anathema to democratic, Bakhtinian forms of dialogism. A genuine, democratic dialogue requires free interanimation of voices, and a degree of equality between interlocutors. They infer that there should be no requirement that consensus should be approached, or that progress (telos) towards some definite endpoint be made (as in Hegel's Absolute). Learning in their ideal dialogues takes place by the voices of others becoming internally persuasive, rather than by learners becoming ventriloquated by the assertions of a monologic, other voice. They go further in identifying the conception of progress and modernity in the Hegelian, Marxist, Vygotskyan tradition as being dangerously monologic and antidemocratic.

Our own work on dialogue in classrooms has similarly been inspired by Bakhtin's dialogism (Ryan \& Williams, 2007; Williams, Ryan \& Morgan, 2014). We have been sympathetic with Bakhtin's followers' distaste for the monologism of transmissionist teaching-to-targets that allows little room for dialogue and the voices of learners. We, among others, assert, for example, that the learners' own often persistent and intuitive or everyday conceptions (often addressed as misconceptions) are an essential part of the classroom learning-teaching dialogue (Fischbein, 1987; Hart, 1981; Hughes, 1986; Ryan \& Williams, 2007). However, we have always coupled Bakhtin's dialogism with Vygotsky's dialectical approach to concepts in what has been referred to loosely as the Cultural-historical Activity Theory (CHAT) tradition (Cole, 1998; Engeström, 1987; R. Engeström, 1995; Roth, 2013). While we recognize tensions between the dia-logic of dialogic pedagogy and the monologism of the curriculum, targets and prescriptions of so-called good practice, we have not understood these tensions as due to a fundamental contradiction between dialogue and progress, but rather between opposing political-economic interests (see Williams, 2011, 2016).

What is at stake here is of professional concern to all those interested in promoting dialogic practices in contemporary classrooms, a key concern for many of us in education in general and mathematics education in particular. If, as some assert (e.g., Matusov, 2011; Wegerif, 2008), the notions of dialogism and dialectics are irreconcilable, and if it can be shown that dialogue cannot live with the notions of 
On the compatibility of dialogism and dialectics

development and progress, we will have a hard time engaging the teaching profession in this notion of dialogic pedagogy, since most stake holders do expect learners to make progress and develop through education.

Any pedagogic innovation or professional development programme in mainstream schooling, in the UK in particular, requires a narrative about how learning outcomes will be improved, and so must have an argument about progress. In this paper, we develop our argument that good dialogue can promote a dialectic that is progressive. Essentially, we argue for both dialogue and dialectic, claiming that the dialectical nature of a dialogue assures that a dialogue can in certain conditions be progressive. This is a key argument and claim that allows us to respect the institutional imperatives imposed by schools, while also arguing for a dialogic pedagogy. Thus, this is not a purely academic, philosophic exercise, but one of great practical importance to professional development.

In this paper, we begin, first, by introducing the key concepts of dialogue and dialectic, from Bakhtinian and Hegelian perspectives respectively. Second, we give the background to our professional development work on dialogic pedagogy and the context of the classroom case illustrative of the theory, our methodological approach, and the particular lesson used to illustrate these ideas in practice. Third, we discuss the dialogue and dialectic of this lesson in theoretical, conceptual terms, bringing out the importance of the dialogue, but also of the crucial role of practice, in this case that of effective measurement, that ensures a dialectic that yields progress. Then the connection with Vygotsky's notions of everyday and scientific or true concepts is made (Vygotsky, 1986). Fourth, we examine the teachers' post-lesson dialogue about the lesson and their pedagogy, arguing that this instantiates a professional dialogism that also offers the potential for progress, to the extent that it engages with pedagogic practice. Finally we draw substantive conclusions for education and reflections on our argument's validity more generally.

\section{Key concepts: dialogue and dialectic}

Dialogue is constituted by a series of utterances between interlocutors, and Bakhtin stresses that each utterance contains at least two voices, that of the author of the utterance and that of an other, a presumed addressee. Each utterance responds to the prior utterances, and demands a response in its turn. When authors speak, they adopt 
On the compatibility of dialogism and dialectics

languages, genres and words given meanings in the past, but populate the utterance with their own intention in responding to previous authors addressed. For Bakhtin, such responses constitute understanding of the others addressed. Followers of Bakhtin use the term dialogism to distinguish Bakhtin's (1981) philosophy of dialogue from the particular everyday understanding of dialogue. Dialogism involves a view of the world and its dialogues as holding multiple meanings determined by contexts of space and time. Holquist (1981) says, "Dialogism is the characteristic epistemological mode of a world dominated by ..." utterances whose meanings are conditioned by "the social, historical, meteorological, physiological" (pp. 426-8). When a discourse is dialogized it becomes "relativized, deprivileged, aware of competing definitions for the same things. Undialogized language is authoritative or absolute" (Holquist, 1981, p. 427). In this sense dialogism is a property that good dialogue can or should have, when participants in dialogue are free and willing to exchange meanings with each other and there is no assertion of authority typical of undemocratic monologic discourse (in no short supply in Bakhtin's experience of exile in Russia in the 1930s to 1960s). Such dialogism is typically richly multivoiced, and new consciousness can arise when participants find other voices persuasive through dialogue (or internally persuasive via an internal dialogue with the internalized voice of the other).

For followers of Bakhtin then, a dialogic pedagogy invokes a pedagogy in which such dialogue is central, with such a democratic ethos, where learners and teachers are encouraged to respond and hence understand. The multiple voices in the classroom may offer sources of dialogue, and both child and teacher might learn from these if they are persuasive. We, along with many others involved in such approaches to mathematics and science education, endorse this approach in principle, but the crux of the matter comes when one tries to implement such dialogism in practice, particularly in a context where the curriculum and institutionalized pedagogy mandates that progress be made against certain objectives and tests laid down for teachers and learners. Dialogic pedagogues assert that this mandating of outcomes in advance cuts against dialogism (again, we agree) and that this follows from the dialectical approach in the tradition of Hegel, Marx, and Vygotsky (but here we disagree).

We agree with the critics that dialectics implies development; but contra some dialogic pedagogues, we do not interpret this as telos in classical terms, that is, as an approach to a definite, already known, endpoint. Rather we associate it with the local progression of the dialectic, where notions are confronted and negated/contradicted by 
practice, and new speculations are put forward that negate the negation. Inwood (1992) actually defines Hegel's dialectic as "involving three steps: (i) one or more concepts or categories..., (ii) ... one or more contradictions (that) emerge in them, and (iii) ... a new, higher category, which ... resolves the contradiction" (pp. 81-2). In practice, we argue this can and usually must include the kind of free dialogue implied by dialogism.

Let us look more closely at the terms, negation and negation of negation (sometimes called positive speculation), which are key to dialectics and the supersession of old concepts by better concepts (this supersession is sometimes translated from Hegel's (1830/2009) German as sublation, but superseding conceptions more naturally signals development and improvement). We elucidate how this works in the contexts of the mathematics classroom and staffroom later, but to take an example from Marx, consider the universal concept of freedom, which was negated by slavery. Marx (1867/1992) showed how slave labor proved inefficient for new industries in the North of the United States, and so the idea of abolishing slavery in the name of free labor became popular even with employers. Free labor is the negation of slavery then, so, the negation of the negation of universal freedom. And yet, this freedom is still circumscribed by the need for the laborer to sell their labor: free labor is in this context wage slavery, which supersedes both prior concepts of slavery and freedom in a new concept, one which combines parts of both, developmentally. The universal concept of freedom has been improved, but may still be developing; Marx suggests free waged labor is negated by capital, and the negation of capital will bring about new practices of labor freedom.

Marx is here thinking dialectically in ways that Hegel put into action throughout his Logic: we are especially interested in this paper in the way that a Universal concept is contradicted or negated in Individual cases in practice, through a Particular case of that Universal that makes it concrete, for example, free labor/wage slavery. (We use capitals here in deference to Hegel's technical terms in the Logic.) This admittedly difficult and abstract idea of dialectic (the Universal-Individual-Particular) will become more concrete as our examples unfold. But one more example might help. Vygotsky (1986) speaks of the way a scientific (Universal) concept can become concrete in a Particular sense, via an Individual case of everyday practice, drawing directly on a materialist, Marxian reading of Hegel's dialectics. In this paper we will present cases from education where this formulation in turn becomes concrete, and in contexts where the activity is explicitly dialogical. The key claim in this paper is that progress (or the 
On the compatibility of dialogism and dialectics

telos) arises when concepts or practices are subject to such improvements by dialectical processes involving negation (or contradiction) and supersession (or sublation), rather than by being driven towards a presumed target or endpoint.

\section{Background: dialogic pedagogy and lesson study context}

In everyday mathematics education terms, we might be concerned with dialogue in mathematics classrooms (between learners and teachers) or in staff rooms (between teachers, or between teachers and researchers, for example those engaged in lesson study). The concern is whether a dialogue goes beyond the sharing of meanings by those involved, to a point where some sort of progress or development is achieved, for example mathematically, or perhaps professionally. Such developments can be said to have telos, if they develop in a progressive direction, according to some criteria.

We draw particularly on our previous empirical research in schools and our lesson study project (Williams et al., 2014) where we have been concerned to develop such dialogues in mathematics lessons. We made use of the lesson study tradition, which in mathematics has focused on problem solving. We often followed the Japanese tradition (also common in the US, see for example Lewis \& Hurd, 2011) of working on knotty mathematics through authentic problem solving processes which produce significant new mathematical concepts or strategies. Thus, lessons often tackled a problem whose resolution required the development of a particular concept (e.g., the circle now seen as a set of points from which all children can fairly throw their hoops at a stick at its center) or a new strategy (e.g., how to divide fractions, as in 9/25 divided by $3 / 5$ ). Such lessons in our work often drew on the children's spontaneous, everyday conceptions (such as fairness) or their prior, familiar mathematical knowledge (they may know how to divide decimals, so 0.36 divided by 0.60 equals 0.60 which is $3 / 5$, say). But a key point in these approaches was fidelity to mathematical norms of argumentation and problem solving, but there is also a certain mathematical telos, that is, progress in learning new, more advanced mathematical strategies or concepts. In this paper, we argue that the process here referred to is often facilitated best through dialogue, and can be faithful to Bakhtinian principles of dialogism: multi-voiced, dialogical, making persuasive voices available. Under these conditions, the telos arises from a dialectic whereby an immediate Universal notion (e.g., of mathematics) is contradicted by an Individual problematic (its negation) that cannot be resolved without 
On the compatibility of dialogism and dialectics

the speculative leap to the new Universal notion that encapsulates the Particular conception involved; (the negation of the negation or the positive speculation).

The focus of the lesson study pertinent in this paper was determined to be the children's experience — including kinaesthetic experience — and associated understandings of the number line, developed through a dialogic pedagogy. The number line represents a range of models and metaphors from counting numbers to the continuum, and can be a powerful instrument in solving problems within mathematics and in applications (e.g., Lakoff \& Núñez, 2000; Williams \& Wake, 2007). We knew from previous research, including our own, that children have some difficulties in using the number line to perform simple calculations such as $15-3$, arising because they count the number line ticks (ordinals) rather than the steps (intervals between ticks). For instance they may count three ticks on the line, thus: $15,14,13$, and say $15-3=13$. We have shown such errors are common (Ryan \& Williams, 2007, p. 94).

\section{Method}

Lesson study originated in Japan and has become attractive worldwide as an inquirybased approach to developing the teaching profession. It is collectively constructed and grounded in the practice, observation, analysis and reflection of groups of teachers focussed on particular "research" lessons. Our approach to lesson study has been reported in detail elsewhere (Williams et al., 2014).

We university researchers formed a lesson study team with a group of teachers and teacher assistants in a local Primary School to explore the agreed focus through joint planning, teaching, and researching specific lessons on the theme of counting on the number line. Lessons were filmed, all children's work collected, and post-lesson discussions/analyses were recorded; in some cases we informally interviewed small groups of children about their work in the lesson or after the lesson. All this was done under a regime of informed consent following research association guidelines that had passed through university ethics scrutiny. At the time of the event described in this paper we had been engaged with this research for nearly three years.

\section{Analyzing the lesson: was there dialogue, and was there dialectic?}

When analyzing the lesson, the lesson study team always began with the learners' work, 
the quality of their engagement and learning: in many lessons we asked the children to write down briefly what they had learnt in the lesson. Such snippets supplemented our notes, photos and video. Inevitably we also discussed what we could have done differently, but also what should be the next steps in learning-teaching.

The children in the class involved in this study counted the steps (strides) made by Usain Bolt in a video of his Olympic 100 metres winning sprint, "The Fastest Man Alive." The class teacher of these 6-year-old children asked them: "How many steps does he make from the beginning of the video until he crosses the finish line?" Figure 1 shows the diagram taken from the lesson study plan.

\section{$<$ INSERT FIGURE 1 HERE $>$}

Figure 1. Shows foot-prints and arrowed steps from the lesson plan

The children could be heard to count quietly as the slow motion video ran, and surprisingly they produced many and varied answers including 18, or 19 (the answers the lesson study team had anticipated, with 19 thought to be correct), but also answers in the $20 \mathrm{~s}$ and $30 \mathrm{~s}$. After several repeated attempts and some discussion about what was being counted, the children's answers converged somewhat and gradually, but there were still differences and the observers tried to work out what the children were doing. Evidently, for some, the counting began and rolled on without much connection with the actual footfalls in the video, while some started with one at the first footfall and for others the one came with the second footfall. The class then moved to the gym where tracks had been laid out with footprints, a start and a finish line.

The children were then led to model the running situation (in small groups) physically, counting the steps using footprints laid out for them along number lines across the gym floor (see Figures 2a, 2b). Groups of children worked together, getting different answers and discussing these, to see if they could understand the different answers within and between the groups.

$<$ INSERT FIGURES $2 \mathrm{a} \& 2 \mathrm{~b}$ HERE $>$

Figure 2a. Jaida's start

Figure $2 \mathrm{~b}$. Children point to their different ways of counting the first footprint

One of the anticipated issues in children's counting of the steps became clear and was 
then discussed as part of the whole classroom dialogue in the gym: should the first footprint (the one at the start line) be counted "one", and what difference would this make to the answer in the end? Another, unanticipated, issue (among others) arose from one of the children counting only up to the last foot-print before the finishing line, and refusing to cross the line from the $18^{\text {th }}$ to the $19^{\text {th }}$ foot-print (see Figure 1).

The children were focused on discussing and explaining different answers which the teacher highlighted: this constituted what we consider to be classroom dialogue situated in authentic problem solving practice, in that it engages multiple voices with a problematic, and there is genuine argument with the aim of reaching understanding of each other if not a consensus.

In this context, then, we ask whether the dialogue makes progress, or has telos, and if so what is its nature, and consider whether it is important, mathematically. On the one hand progress in the classroom dialogue here might have been considered to be the result of some or most of the learners coming to agree with the teacher's preferred understanding of the situation and the mathematics, for example a convergence on an agreed answer of 19 steps. This view is prevalent in classrooms which are driven by the teacher's conceptions of the presumed right answer, and we counter this by making sure that we teachers stay silent on our preferred answers, at least to begin with. Many teachers we have worked with find it requires a real effort of will to stay silent and just listen rather than simply tell the children their preferred, notionally correct answer. Indeed, many children — used to a traditional, target-driven pedagogy — spend their time in class trying to guess the teacher's preferred answer (see also Holt, 1982). But convergence on the teacher's preferred answer could be argued as one version of telos and perhaps this is the kind of telos of so-called dialectic that dialogic pedagogues dislike, because arrival at the presumed endpoint takes precedence over the need for a persuasive (or an internally persuasive) discourse.

On the other hand, one might think progress in the dialogue arises due to the teachers' and researchers' engaging with and understanding the children's mathematics and their perspectives on the practice. Bakhtin (1981) theorizes a dialogue as monologic if the authority asserts their voice, but as dialogic if discourse is engaged such that both subjectivities have an opportunity to dialogue, taking the other's discourse and consciousness into consideration, so thinking about making the other's arguments one's own. Such dialogism then might involve progressive change in understanding, and to that extent we argue this process would be progressive by virtue of being subjectively 
On the compatibility of dialogism and dialectics

dialectical. Such progress may have many virtues, but what if that progress is in fact towards mathematically backward ideas?

The question arises, then, whether this subjective progress represents objective telos in mathematics, that is, can the dialogue be said to advance mathematically, sharing more advanced mathematical understandings, in an objective, historical-cultural sense? The simplest and simplistic answer to this conundrum might be that the teachers', researchers', and the prescribed curriculum's mathematics-assuming alignment with the curriculum, and assuming that the curriculum is in turn not mistaken in relation to the cultural-historical state of mathematics - will be more advanced culturally than the children's mathematics. (It must be admitted here that this is an assumption that many hold to be implicit in Vygotsky's notion of children's spontaneous concepts up against the school's scientific concepts: a point we return to below). The telos then is here typically defined by the definition of the mathematics in the curriculum targeted by the teacher (again, telos as targeted endpoint: end of story). In this view the dialogue is functionally developmental if and only if it allows the 'correct' mathematics to become internally persuasive for the children: this is what Matusov criticizes as monologic in Bakhtin's terms (Matusov, 2011). We will now argue that Hegel-Marxian dialectics might offer another perspective: in true dialectical terms, we seek a new supersession of these two positions.

\section{Theoretical argument and dialectics}

We agree with Matusov (2011) that the dialectic implies a notion of progress, that is, a teleological process, but the actual end-target may not be anywhere visible during the process itself, either for the teacher or the learner. Only from the vantage point of history can one see with any certainty whether progress was made, or where some endpoint was reached. As Hegel (1830/2009) pointed out, the "owl of Minerva" takes flight at dusk: he meant that philosophical speculation takes place in reflection over the day's activity, and is therefore historical with respect to activity. Nevertheless, the dialectical process that takes a notion (e.g., mathematics, or counting) through its negation, to its supersession in a new notion, can be regarded as in itself progressive or developmental (for notion here we might also say idea or concept or conception as long as these are not identified with Hegel's technical terms for categories that he usually capitalizes). It is the process of negation and supersession in Hegel (1830/2009) that characterizes this type of progress and teleology. We consider now why this is so. 
Supersession requires that the notion and its negation are both destroyed and preserved, and so unified in the speculative creation of a new notion (this is often simplistically presented as a synthesis of a thesis and its antithesis - a formulation due to the philosopher Fichte, according to Inwood (1992). That is, the original notion and its negation do not disappear completely, but are both (partially) destroyed and (partially) preserved when superseded within the new. As such, the new notion represents progress from the old to a new level of thought, which Hegel (1830/2009) calls development in his doctrine of the concept (see also Blunden, 2013). Indeed, this dialectic is present throughout the Logic: Hegel begins with the notion of being as the simplest, immediate (and vacuous) notion of ontology; its negation is non-being or pure nothing. The supersession of being and non-being is then becoming, that is, the movement from nothing to being something (and additionally from being to nothingso dying is also a kind of un-becoming, as unbecoming as it sounds). Curiously Bakhtin has himself built his processual view of dialogism on the infinite nature of this becoming, suggesting a lack of closure, a lack therefore of the target or Absolute. The result is something specific, a determinate being located in place and time, with a certain quality (and quantity, and thus measure) distinct from other determinate beings elsewhere, and otherwise.

In sum, the notion of becoming preserves/destroys but dialectically supersedes pure notions of being and nothing, but now in a dynamic sense and not in their previous, static, immediate form; they are preserved but superseded because each is now mediated by its other, its negation.

Where do these superseding categories in the speculative moment of dialectic come from? Where did the creative category of becoming come from? We know in this particular case Hegel (1830/2009) drew from the Eleatics (pre-Socratic school of philosophers), but in general it is not clear where Hegel's creative inspirations came from, and we do not think they are logically determined in the classical sense, but rather arose themselves from his own reflections on history (and in that sense perhaps ultimately had a material basis in activity).

Similarly, in Hegel's (1830/2009) second part of the Logic, the essence of being involves a dialectic of opposites, from existence (the identity-difference contradiction) to actuality, through dialectics of appearance (content-form, and whole-part relationships and so on). In each new, superseding notion these opposites are preserved, but only in their relationship to, and mediated by, each other. For example, when 
On the compatibility of dialogism and dialectics

identity is mediated by difference, it becomes a differentiated, mediated identity. Vygotsky (1986) used this idea when he said that we become ourselves through others - note the multiplicity of relations with others here - and this neatly parallels Bakhtin's dialogism.

We can argue that in order to maintain ourselves in the hurly-burly and challenges of the real world, in order to keep on being who we essentially are from day to day, we must change and sometimes even develop. One's identity as a teacher for instance, means adjusting to learners, and so one maintains one's pedagogic identity, perhaps as a dialogic pedagogue, by becoming somewhat different day after day. This quality of development may also be expressed in Hegel's (1830/2009) doctrine of the concept: the dialogic pedagogy (the developing, Universal concept) is constituted as a Particular pedagogy in an Individual lesson. So, the Universal is here contradicted in cases of Individual learning-teaching practice or experience, when the Particular dialogue fails or operates in some new way. Successive negations in practice allow the dialogic pedagogy to develop and become more and more concrete in its Particular pedagogies. (Here again we use capitals in deference to Hegel's Logic, but see Vygotsky's (1986) use below.)

One also can understand the notion of number as developing in this way: the notion of whole number is negated in the practice of measurement, by the fact that not all measures can be counted by whole numbers (maybe not even steps are always wholes). New numbers are demanded in practice to measure with; hence fractions or decimals. But then these rational numbers supersede the whole number and its practical negation. Whole numbers (and their negations, the entities they cannot measure) have not disappeared here, they are preserved in a new form. Thus, the whole number one perhaps becomes a rational number, let us write it as 1.0 here for the moment, which can be identified with and yet is not quite the same as the whole number one that was negated. A measurement of 1 meter may in some competent practices be taken as identical to the measurement 1.0 meters, in some meaningful sense, but the number 1.0 is understood as a measure in relation to other rational values such as $1.1,1.2, \ldots$ and so may have other meanings than the whole number 1, understood in relation to its successor 2, and other counting numbers.

In this account the concept of practice has been adduced, especially in the notion of competent mathematical or measurement practice, or authentic dialogic pedagogy. The Hegelian dialectic was originally presented as being the logical movement of 
"thought" in itself, and the concept of social practice in this engagement is usually stressed as Marxian. But for Marx (1939/1973) conscious thought is still a key moment in practice, just as for Hegel (1830/2009) pure thought becomes a more concrete expression of truth through its reflections on activity.

Thus, in the preceding supersession, the practice of counting in new contexts negates the old idea and pushes new thought: the cognitive conflict induced provides one contradiction in thought-and-practice, in the subjective moment of thought and in the practice of measurement. Contradictory positions in the practice and the associated dialogue provide other contradictory moments in the discourse in practice (in the objective moment in dialogue respectively). Ultimately what produces the rational numbers is the efficacious resolution of the concept of number in the whole system of measuring practices which serve as the developmental testbed (both historically, and perhaps in the classroom, as our case might suggest).

Here Marx and Lenin's materialist readings of Hegel and the dialectic become relevant: we recall that Vygotsky (1986) appealed to both in this famous passage in Thought and Language, quoting volume 29 of Lenin's collected works as follows:

Man's practice, repeated a billion times, anchors the figures of logic in his consciousness. These figures have the strength of prejudice, their axiomatic character, precisely (and only) because of this repetition. (p. 198)

Ultimately, for Marx, and here Lenin and Vygotsky, the dialectic of theory and practice is developmental to the extent that thought proves efficacious in practice, where the abstract becomes concrete. As such, intersubjective dialogue (e.g., between learners and teachers, and the curriculum, and the community of mathematicians) provides a powerful contradictory moment for dialectics in discourse, but material practice (including relevant discourses) is ultimately decisive. Dialogue without a practical context that proves a notion may not be decisively developmental. But often the grounding of dialogue in practice is highly implicit and indirect, especially in mathematics. We easily lose sight of the grounds of mathematics in classrooms, where the justification for its axioms and concepts have been lost, and schooling may fall back on the teacher's authority, or intuitive correctness, as a substitute.

Thus, Marx (1939/1973) used Hegelian dialectics himself in thinking through his analyses of capital and labour in the Grundrisse: most obviously, he posits that 
labour is the negation of capital, and capital - in order to conserve, renew or supersede itself - must be negated through its investment in labor, and through the creation of surplus value capital-and-labour become superseded in new, expanded capital (and ever more impoverished proletarian labor). Otherwise capital would never emerge from a pre-capitalist form of money as pure circulation (Marx, 1939/1973).

In the context of measuring Usain Bolt's footsteps, as we researchers and teachers thought and talked about the children's answers ("Was it 18 or 19 steps?"), we saw that both were correct answers, if only to different, or differently mathematized questions, and that the truth might even be that the answer is in both, or somewhere between the two, depending on what we choose to mean by the term step. The team achieved this new mathematical understanding through the negation of our original notion that we had the answer as 19; this was achieved in our joint lesson experience in practice with the children's mathematical work, shared in dialogue but also tested in competent practice (see this in relation to use value of mathematics, in Williams, 2016).

Some of the children themselves seemed to have developed their understanding of measurement in this lesson also: their counting of their own steps in the gymnasium became more manageable and accurate than counting steps on the video, and they were able to represent the counting process in diagrams on posters (more or less close to Figure 1) explaining how they had come to different results. Some children were also able to articulate (clearly enough for us to follow) why they had changed their minds or what had made them change their minds in the process.

We claim that these developments of understanding by the team and the children can be called progress in terms of the previous discussion, but one in which dialogue is crucial. First, there was dialogue in which the teachers and children shared their understandings and came to better understandings of each other's mathematics. Second, the practical counting involved made these ideas of counting and number concrete in a particular case, that is, a case in which one could see the different ideas in action, and one could judge their competence against practical criteria. Thus, one could see the different children counting the first footfall as one or two, and one could see when a child has stopped running before the finishing line, because they are at the end. The teaching-learning in the dialogue between teachers and children can be genuinely dialogized, we argue, but it is more than this, because it is tied to a concrete practice in which ideas have to prove their efficacy, whether or not they are proffered by a child or adult, student or teacher. The voice of the other becomes persuasive in practice, and the 
teacher may be persuaded by the child as well as child by teacher. The result is not just progress through dialogue, but objective progress of the dialogue and of mathematical competence in practice.

We should also comment here on Vygotsky's (1998) conception of spontaneous and scientific concepts, in which we claim a very direct connection to Hegel's (1830/2009) notion of the concretisation of the Universal or general concept (especially clear in his Logic in the Doctrine of the Concept). Vygotsky is understood to posit the concepts of everyday lived practice as spontaneous in contrast to those taught in school that might be called academic or scientific concepts. The downward-growing schooled concepts have to entwine with the upwards growing and multiple spontaneous understandings of the learner to forge true, or real scientific concepts.

As Vygotsky (1998) says:

A real concept is an image of an objective thing in its complexity. Only when we recognize the thing in all its connections and relations, only when this diversity is synthesized in a word, in an integral image through a multitude of determinations, do we develop a concept. According to the teaching of dialectical logic, a concept includes not only the general, but also the individual and particular. (p.53)

This process fits our assertion of a Hegel-Marxian dialectic, where the test of the concept in practice is effectively the entwining of the science with the multitude of everyday practices with which the general scientific conception becomes entwined. For Hegel, the relatively abstract, immediate, Universal conception meets its negation in an Individual case, where the concept has a Particular meaning, which can fold into a new, fresh understanding, a superseding Universal conception. So, the Particular is superseded into a more concrete and so more true Universal (one that has been mediated by the Individual and its Particular instances in which the Universal made sense).

In the account above, then, it is not the case that the teachers' or the curriculum's mathematics is the true scientific mathematics. The true is that which comes to be understood through the learners entwining it concretely with their everyday knowledge. Thus, the true concept is what emerges from this dialectical, learningteaching process of entwinement. The initial presented curriculum is scientific but not yet concrete and so not yet true: maybe it will come to be true through the learners' and teachers' joint activity and dialogues. And then we can always be sure that the true concept that results will not simply be an internalized reflection of the curriculum 
On the compatibility of dialogism and dialectics

concept, but will have been refracted and transformed by the learning-teaching activity, often in ways not foreseen by the dialogic pedagogue.

In the next section we look at the dialogue of teachers discussing this very lesson in their lesson study reflections, and look for similar dialogism and dialectics in professional development.

\section{A lesson study dialogue and/or dialectic?}

The particular lesson event described above involved the entire school staff in the lesson study observation and an extensive after-lesson discussion on a whole school professional training day (the children kindly agreed to come in for the lesson study event on a voluntary basis). The two themes of the post lesson study discussion that emerged were: how would we teach this lesson again, and/or what would we do in the follow-up lesson? This lesson study approach follows the widespread model of research-led continuing professional development cycles, though we have adapted it for local conditions and to focus on both classroom, and staff room dialogue (see Williams, et al., 2014).

\section{Transcript of lesson study reflections}

In the following transcript, we report part of the dialogue reflecting on the experience of teaching and observing the children and the way the teachers and researchers imagined developing new teaching practice, based on this experience. This can, we suggest, be understood as dialogism: the teachers and researchers were engaged in trying to make sense of the experience and to make sense of each other's sense of what occurred. But is there a dialectic, is there progress/development, and is there a relation between dialectic and development? The teacher who led the class (typically a collective group plans and supports the lesson, but the teacher who knows the children and usually is their class teacher leads in organisation and classroom activity/discourse) begins this dialogue by asking how to handle a classroom dialogue engaging with the two productively different answers discussed above: 
$1 \quad$ Teacher 1:

... two different answers... And so - it could be this answer, it could be this answer ... and actually get the children to be involved in deciding why one answer or the other ... and effectively ... those who think it's 18 , and those who think it's 19 ... We're not saying this is the definitive answer, we are just saying it is one that could be explained ...

Researcher 1: I think we want to get to what Jaida [pseudonym, one of the children] said where you count, (from) where the zero is ... and historically that's what humankind ... had this problem ... so I'd suggest, yes, how did these people get 18 , how $19, \ldots$ so they're engaged ... so we get: they got 18 because they started counting here, that's what we want articulation of ... These people call this foot-print "one", and they call it "zero" ... so once you have that out on the table you ... then you can start a debate. So which...

Teacher 1: If you do that, aren't you going to be giving them (an) answer already? If you are saying this is one or zero, aren't you? Whereas if you ask them the reasons for two answers, you aren't explaining why... it's up to them to prove or disprove ...

Researcher 1: Yes, I'm saying how did these children get 18, how 19... and they have to come back and say ... because they started the one here and they started the one there ... and then you might get ... Who's the little girl who got down [bending down on one knee as if starting a race] and said that ...? ... Because there is miscounting from either one or zero ... because it's not a convention, it's sensible: there's the step, from a starting point so the one is out there ... (gestures to the end of the step).

Teacher 2: Then the, the ...we want the rest of the class to be standing round to watch them do that (gestures to the circle the class would form) ... because I had to get Denis [pseudonym, one of the children] to come down ... and they're not used to having to look and listen to that group that's saying something important... We found when doing the project in the past that it took some lessons for them to get the idea that, 'hold on, I need to stop and listen and look to what they are saying, that has something to do with $m e$,' and I think to get them round one of the group's number line and get them to act out what they were doing 
On the compatibility of dialogism and dialectics

again, so that they are there seeing the number line together as well, I

think that's something I'd want to do in the next lesson as well. 


\section{Dialectical process}

We now consider this dialogue as a series of reflective-imaginative moments in a dialectical process:

Teacher 1 asks "Could you not give two different answers...? And so - it could be this answer, it could be this answer ..." (lines 1 to 5). Here the presumed answer "19" is contradicted, that is, confronted directly with its opposite, the diversity of children's spontaneous, multiple productions. Teacher 1 says “ ... and actually get the children to be involved in deciding why one answer or the other ..." (lines 14 to 17$)$. Here the children are imagined to participate and engage subjectively with the mathematical alternatives in their classroom dialogue (which had to some extent actually occurred in the studied lesson). They are asked to reason on a relatively equal basis, dialogically, about the mathematics with others, as subjects of different mathematizations, in a dialogue reflecting the opposition of ideas. But the opposition of these ideas reflects their mathematical negation in the measurement practice, which for Hegel-Marx is the traditional negating dialectical moment. How can this be resolved, except in a new, speculative supersession of the better of the two - the conception and its negation?

Researcher 1 then (lines 6 to 13), seeing the historically important idea as being the difference between zero and one (as the ordinals on the footprints on either end of the first step being counted) imagines that one of the children's (Jaida's) mathematics could enter this debate: the key mathematical mediation is the zero reference point for beginning the counting. This explains how the mathematically opposing objects (the counting to get 18 versus 19) become superseded in a new mathematical understanding (viz., where you start counting from or the counting of foot-prints rather than steps , i.e., how the task is interpreted and modelled, and so how a step is interpreted).

Teacher 2 says "And then you might get ..." (lines 25 to 35) imagining now how this dialectic might come into being in her future classroom dialogue: the little girl who showed, from her subjective point of view, why it is sensible to count the foot-print at the end of the first step as one, finishing the first step, and justifying this mathematical choice/answer in her interpretation.

Researcher 1 (lines18 to 24) participates in the little girl's sense-making with her own gesturing, revealing why (and objectifying how) the end of the step should be counted or signified as one. This subjective sharing is offered as a generalization, and 
On the compatibility of dialogism and dialectics

therefore as a plan for the future lesson being imagined. The completion of the professional dialectic would become verified in a new practice in another Individual lesson, a new particular instance of their developing dialogic pedagogy.

Teacher 2 (lines 25 to 35 ) accepts this conception, and starts to envisage concretely how this could work in her future embodied teaching practice (a concretization of the abstract, universal notion). She imagines how the debate might easily malfunction (as in past experiences) and she explains how the children need to be gathered together to facilitate such a meaningful dialogue on the focal step, that is, one where the contradictory subjective positions are articulated and engaged, so negation can take place in the learning-teaching practice. This is imagined through the recall of previous lessons where she had done this kind of practical dialogue: her gestures represented the envisaged arrangement in the future class interactions. The dialogic movement from the lesson experience and its study has now shifted to imagining how the lesson might have been, or what the next lesson might become next time.

We now consider this dialogue and its telos. Yes, the dialogue itself represents progress as the teachers share ideas and they make sense of each other's subjective ideas in so far as they become persuasive. But the concrete reference of this dialogue to a particular lesson that was mutually shared provides the anchor in practice that potentially offers something like telos, that is, the development of theory that addresses a more efficacious competent professional practice.

\section{Progressive dialogue}

In previous work we have described this kind of lesson study dialogue as offering a zone of proximal development for the teachers and sometimes for the whole profession's teaching practice, which we called a zone of professional development. Such a dialogue can only be conceived as developmental in Vygotskyan terms if it is indeed teleological, for example, if the teacher's professional practice is seen to be making progress towards something better (i.e., more practically efficacious). We do not know what the end-point of professional practice is until after it has developed (after dusk), but we can perhaps see in the dialogue the dialectic of development that our theoretical argument requires: its process is dialogic, but with dialectical potential.

How so? The teachers were prepared to deal with alternative, potentially negating positions or arguments from other colleagues or researchers; but they were 
On the compatibility of dialogism and dialectics

also committed apparently to testing the alternatives in practice, even if the practice discussed was an imaginative one. What makes for true progress in this dialogue is the (maybe imaginative in this moment) efficacy of the notional pedagogy in future practice.

Arguably, then, what makes this dialogue progressive is the supersession of notions with their negations in the new notions imagining future practices: we do not know for certain that these new notions will be progressive until practice is confronted in the future, whereupon no doubt new contradictions will arise. Let us stress once again that the negations in practice are essentially multiple, and that a theory of development here demands multivoiced dialogues, tested through multiple individual cases in practice to become developmental, and so professionally persuasive. This is not a matter of progressively approaching a pre-conceived targeted pedagogy, but is indeed infinitely open.

\section{Substantive conclusion for education and professional development}

Our argument is that dialogue should be but also can be (as we evidenced in mathematical and professional contexts of practice) developmental, if it is dialectical, and that the dialectic requires not just a dialogue between opposed positions/notions, but a concrete dialogue in which the undeveloped notion is discussed in the light of its negation in practice.

Development then can — though of course not with certainty — arise through a genuine progress in which the undeveloped notion and its practical negation are superseded and so both destroyed and conserved in the new notion. The negation sometimes may involve a purely discursive, verbal, dialogical moment of negation, where protagonists argue their different points of view. But at root of some, perhaps many, developments there lies a negation in practice; the validity in developing and advancing thought is dependent on its relevance and efficacy in practice. Hegel (1830/2009) (and Marx, 1939/1973) describes this as superseding the universal (general, theoretical) notion in the individual practical activity, in which the universal idea is particularized, thereby ascending from the abstract to the concrete.

We can consider that cases may occur where this dialectical moment does not arise, and dialogue leads to no particular dialectical moment, perhaps where each argument is tested against its opposition without effectively being negated. Yes, dialogue can occur without consensus, and without progress, and without significant 
On the compatibility of dialogism and dialectics

collective development. But while this quality of non-developmental dialogue may have merits, this does not necessarily meet all the needs of education.

\section{Conclusion}

In conclusion, let us consider the implications for education in general and mathematics education as its particular case, and the naïve alternatives put forward in the introduction. Bakhtin's theory of dialogism provides a rationale for the importance of persuasive dialogue with the other: thus the teachers' and the curriculum's mathematics must be made persuasive for effective learning to take place, and we can reject monologism that is based on arbitrary, unequal power relations, such as when the learner is expected to unproblematically accept what the teacher declares as the truth (which effect Vygotsky, 1986, associates with a pseudoconcept). In what way can the learners' and teachers' voices be equal in the inevitable power relations in the real classroom, given that the teachers' and the curriculum's perspective has centuries of culturally-historically evolved practical science behind it?

Materialist dialectics requires that dialogical persuasion be based in efficacy in practice: the teacher as mediator of the curriculum may introduce tasks that engage the classroom community in contradictions of given notions with practice (e.g., by selecting from the culture tasks in situations that "beg to be organised" by appropriate concepts, as Freudenthal, 1986, p. 32, put it). The teacher and curriculum can thereby arrange for dialogues in which contradictions are developmental because practice negates inadequate notions; and new notions develop in which the old are superseded. The dialogues are essential to the process, but not in themselves sufficient to generate this dialectic.

This of course applies equally to professional development processes as it does to the children's cultural development. Well-designed professional development should confront undeveloped theoretical ideas with challenges through classroom practice: genuine development occurs when, and because, professional notions are contradicted (and so shown inadequate) in practice and superseded in dialogue and, decisively, in further practice. We should perhaps celebrate and publish lesson study accounts of such inadequacies in classrooms much more than we usually do: they may be the life blood of real professional development. 


\section{Reflections in dialogue and dialectic in development}

From a practical point of view, it is vital to bear in mind that this whole discussion takes place: (1) in the context of working on dialogic pedagogy - broadly the effort to create dialogue in learning-teaching, and (2) as a critical pedagogy, that is, one that challenges inadequate (and unjust) pedagogies and leads to development of more efficacious and equitable activity.

As such it is not intended to weaken the move to dialogism. On the contrary, we are convinced that dialogue in classrooms challenges most institutional, monologic practices. However, we go to dialectics as a means of ensuring that dialogism isn't counterposed to development. We do not want to do away with development, as posed by Vygotsky's dialectical development of true concepts, which Hegel posits as the concretisation of universal conceptions in the singular, Individual and Particular of the notion (or for Vygotsky: scientific concepts in everyday practice). And we claim that this approach to development can be understood as giving more equal weight to learners' voices, insofar as it values their everyday understanding and practice in the formation of true scientific concepts and practices.

This raises a number of questions that we have not fully resolved in this paper. One question concerns where the key cultural resource for the speculative moment in the dialectic comes from. In the text we analysed, it was suggested that this can come from research and history, and we mentioned Freudenthal's (1986) notion of studying the cultural roots of mathematical ideas. In general some would say a three dimensional curriculum should offer this, rather than vacuous abstract concepts with little or no concrete cultural connections (in relation to the above example one might for instance expect to see a comparison of the control boards on elevators in the US 1,2,3... and Europe $0,1,2, \ldots$ mentioned in curricula). In much lesson study work we find a major proportion of our time is spent working on making our abstract curriculum more concrete, asking questions like "Whatever happened to the decimetre?" and "How do they decide the minimum height of a child for the Big Rollercoaster?"

Nor have we here rehearsed the power relations involved that curtail the free development of dialogue in classrooms or in professional development activity. For instance, it is unlikely the lesson we discussed here would have happened if it were being officially evaluated - in our current regime, a lesson is not graded outstanding if it does not provide evidence of every child having made progress during the actual lesson. This proves to constrain the sorts of lesson events that take place for such 
supervision, and as surveillance becomes more and more internalized, not only in events being externally inspected.

In this context, and in the context of regimes imposing more and more compliance on teachers and schools, the resistance to monologic notions of progression and development expressed by proponents of dialogism is wholly understandable. We have argued that a dialectical perspective allows one to situate development and progress within a dialogical framework, and that dialogism can be shown to be an essential part of it, evidenced in the classroom and the professional development context.

What we have not yet done here is to elucidate the philosophical, or logical, synthesis of the concepts of dialogism and dialectics, which will require another investigation. In our reading we repeatedly find multiplicity and open-endedness denied of dialectics interpreted by Bakhtin and his followers, for example, in the negations of a Universal notion by a plurality of Individual cases where it is obliged to subsume Particular contradictory in multiple practices and subjectivities. Even Bakhtin's insistence on internal persuasiveness is implied by the significance of multiple, individual spontaneous conceptions of different voices in different practices. But ultimately this theorization demands empirical support in practice. We assert, then, that the evidence of practical experience given in this paper contradicts the general proposition of incompatibility or irreconcilability of dialogism and dialectics.

\section{References}

Bakhtin, M. M. (1981). The dialogic imagination (C. Emerson \& M. Holquist, Trans.). Austin, TX: University of Texas Press.

Bakhtin, M. M. (1986). Speech genres and other late essays (V. W. McGee, Trans.). Austin, TX: University of Texas Press.

Blunden, A. (2013). Concepts: A critical approach. Chicago, IL: Haymarket Books. Cole, M. (1998). Cultural psychology: A once and future discipline. Cambridge, MA: Harvard University Press.

Engeström, Y. (1987). Learning by expanding: An activity theory approach to developmental research. Helsinki: Orienta-Konsultit.

Engeström, R. (1995). Voice as communicative action. Mind, Culture, and Activity, 2(3), 192-215. 
On the compatibility of dialogism and dialectics

Freudenthal, H. (1986). Didactical phenomenology of mathematical structures. Mathematics Education Library, 1, Springer.

Fischbein, E. (1987). Intuition in science and mathematics: An educational approach. Dordrecht: Reidel.

Hart, K. M. (Ed.) (1981). Children's understanding of mathematics: 11-16. London: John Murray.

Hegel, G. W. F. (1830/2009). Logic: Being Part One of the Encyclopedia of the philosophical sciences (W. Wallace, 1883, Trans.). Pacifica, CA: Marxist Internet Archive.

Holt, J. (1982, revised edition). How children fail. New York: Delacorte Press.

Holquist, M. (1981). Glossary. In M. M. Bakhtin, The dialogic imagination (pp. 423434). Austin, TX: University of Texas Press.

Hughes, M. (1986). Children and number: Difficulties in learning mathematics. Oxford: Basil Blackwell.

Inwood, M. (1992). A Hegel dictionary. Oxford: Blackwell.

Lakoff, G. \& Núñez, R. E. (2000). Where mathematics comes from: How the embodied mind brings mathematics into being. Basic Books.

Lewis, C. C. \& Hurd, J. (2011). Lesson study step by step: How teacher learning communities improve instruction. Portsmouth, NH: Heinemann.

Marx, K. (1867/1992). Capital: A critique of political economy. Volume 1. London: Penguin Books.

Marx, K. (1939/1973). Grundrisse: Foundations of the critique of political economy (M. Nicolaus, 1939-41, Trans.). London: Penguin.

Matusov, E. (1996). Intersubjectivity without agreement. Mind, Culture, and Activity, $3(1), 25-45$.

Matusov, E. (2011). Irreconcilable differences in Vygotsky's and Bakhtin's approaches to the social and the individual: An educational perspective. Culture and Psychology, 17(1), 99-119.

Palm, R. (2009). Hegel's concept of sublation (Doctoral dissertation). Retrieved from https://irias.kuleuven.be/bitstream/123456789/234670/1/PALM+dissertation.pd $\underline{f}$ 
Roth, W.-M. (2013). An integrated theory of thinking and speaking that draws on Vygotsky and Bakhtin/Vološinov. Dialogic Pedagogy, 1. Retrieved from http://dpj.pitt.edu/ojs/index.php/dpj1

Ryan, J. \& Williams, J. (2007). Children's mathematics 4-15: Learning from errors and misconceptions. Maidenhead: Open University Press.

Vygotsky, L. S. (1986). Thought and language. Cambridge, MA: MIT Press.

Vygotsky, L. S. (1998). The development of thinking and formation of concepts in the adolescent. In R. W. Rieber (Ed.), The collected works of L. S. Vygotsky. Vol. 5. Child Psychology (pp. 29-82). New York: Plenum.

Wegerif, R. (2008). Dialogic or dialectic? The significance of ontological assumptions in research on educational dialogue. British Educational Research Journal, 34, $347-361$.

Williams, J. S. (2011). Towards a political economic theory of education: Use and exchange values of enhanced labor power. Mind, Culture, \& Activity, 18(3), 276292.

Williams, J. S. (2016). Alienation in mathematics education: Critique and development of neo-Vygotskyan perspectives. Educational Studies in Mathematics, 92(1), $59-73$.

Williams, J., \& Ryan, J. (2013). Research, policy and professional development: Designing hybrid activities in third spaces. In V. Farnsworth \& Y. Solomon (Eds.), Reframing educational research: Resisting the 'what works' agenda (pp. 200-212). London: Routledge.

Williams, J., Ryan, J., \& Morgan, S. (2014). Lesson study in a performative culture. In O. McNamara, J. Murray \& M. Jones (Eds.), Workplace learning in teacher education: International practice and policy (pp. 151-167). Springer.

Williams, J., \&. Wake, G. (2007). Metaphors and models in translation between college and workplace mathematics. Educational Studies in Mathematics, 64(3), 345371.

\section{Figures (1 Word, 2a, 2b TIF images)}




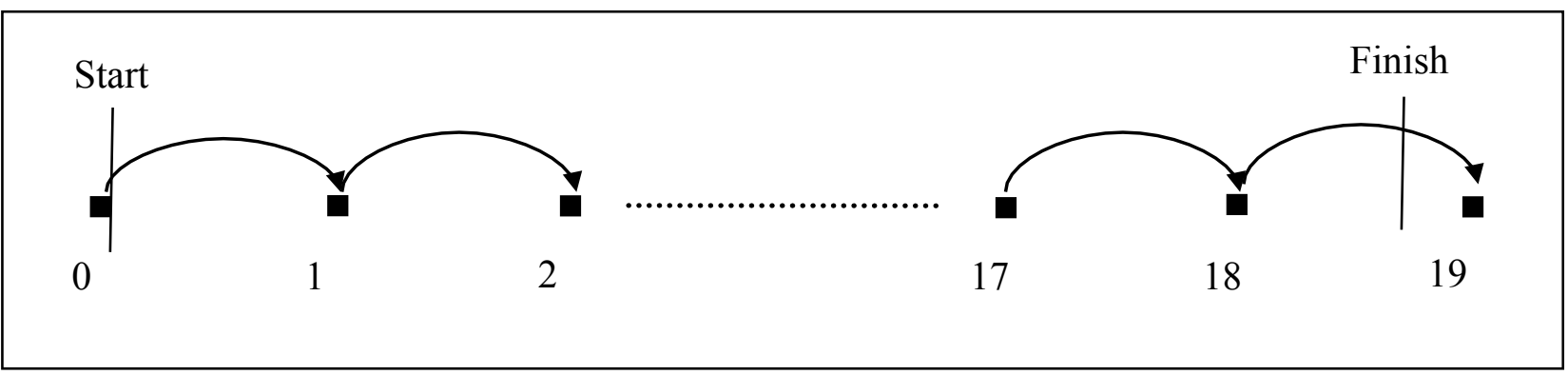

Figure 1. Shows foot-prints and arrowed steps from the lesson plan

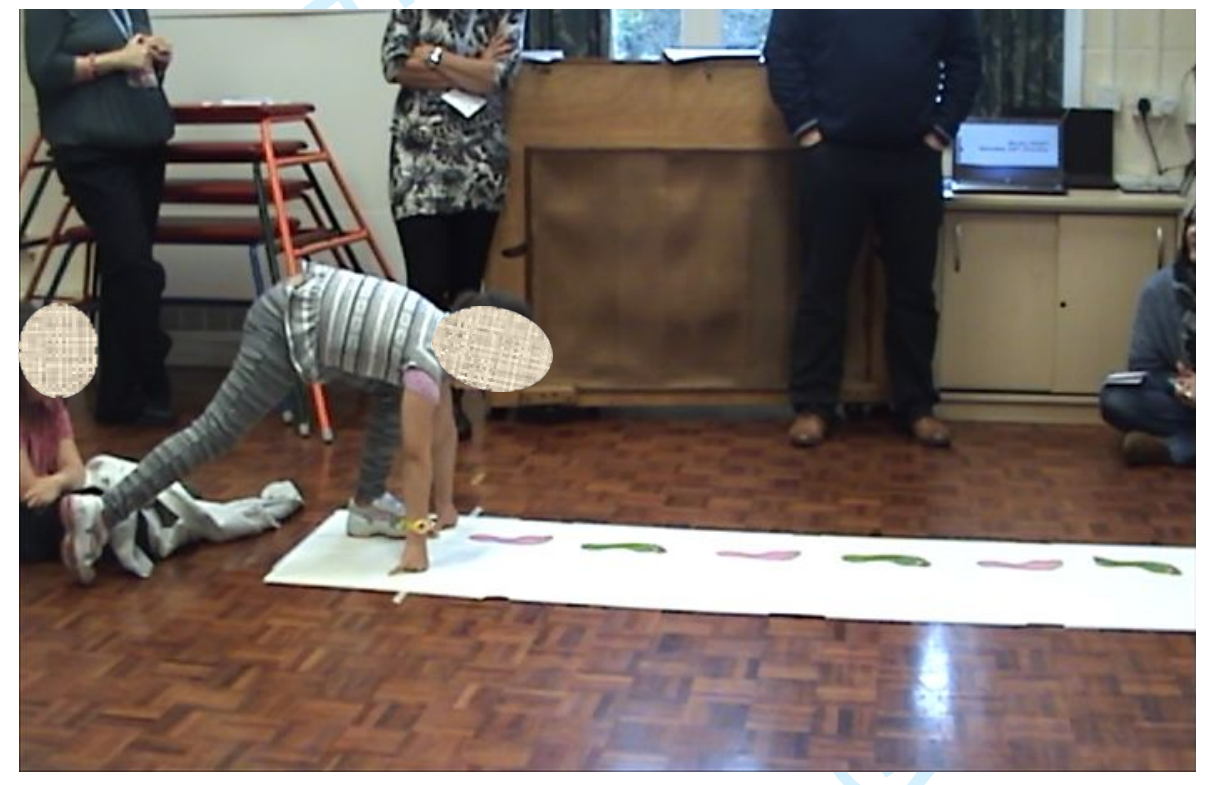

Figure 2a. Jaida's start

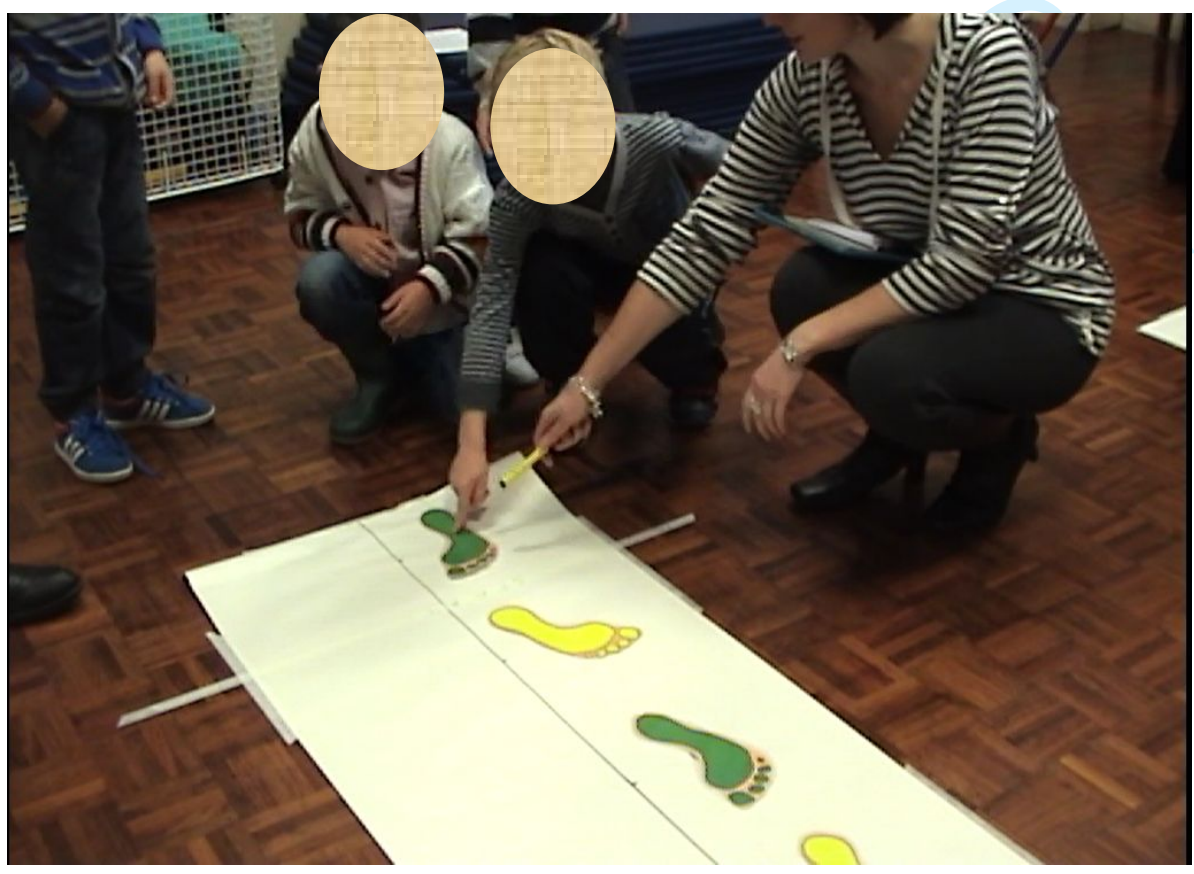


On the compatibility of dialogism and dialectics

Figure $2 \mathrm{~b}$. Children point to their different ways of counting one 